\title{
Colour Psychology in Art: How Colour Impacts Mood
}

\author{
Ali Redha Hussain \\ The Higher Instate of Dramatic of Arts, Kuwait City, Kuwait \\ Email:dr.aliuk19@yahoo.com
}

How to cite this paper: Hussain, A. R (2021). Colour Psychology in Art: How Colour Impacts Mood. Art and Design Review, 9, 301-308.

https://doi.org/10.4236/adr.2021.94025

Received: August 10, 2021

Accepted: September 15, 2021

Published: September 18, 2021

Copyright $\odot 2021$ by author(s) and Scientific Research Publishing Inc. This work is licensed under the Creative Commons Attribution International License (CC BY 4.0).

http://creativecommons.org/licenses/by/4.0/

\begin{abstract}
This paper uses a qualitative approach in examining the role and potential uses of colour psychology in arts practitioners and art students, looking specifically at the effects of colour on how subjects understand and process complex psycho-emotional phenomena. So, this paper is focused on ways artists use colour to deal with emotion, how this effect cognitively operates, and may have second-order effects on arts spectators. Colour psychology is initially considered from a clinical research perspective, vis-a-vis its utility, via art therapy, as a psychological curative. Next, the transposition from art therapeutic contexts to art production is examined: how psychological and cognitive processes potentially benefit students and artists alike, in related though distinct ways regarding metacognition and behavioural self-regulation. Finally, this study examines the work of four artistic masters, Piet Mondrian, Pablo Picasso, Edvard Munch, and Wassily Kandinsky, analyzing the relationship between mood and mind state (of the artists) and the colours the artists use in their works.
\end{abstract}

\section{Keywords}

Colour Psychology, Art Therapy, Metacognition

\section{Introduction}

Colour is "generated by interactions of light and matter atoms and molecules (Tilley, 2010) the electrons associated with these", and is "defined as the subjective appearance of light as detected by the eye". How eye "perceives" colour is a result of an "eye-brain combination" which "serves to discriminate between the light of different wavelengths or energies" (Tilley, 2010). Colour, empirically, is a perceptual by-product of atomic and sub-atomic interactions at the molecular level, a ubiquitous phenomenon in the material world. The human experience is 
steeped in colour, shaping how we interpret matter (particles and fields). Colour continually surrounds us and mediates our perceptual experiences, comprising a continuous interpretive "event". Our experience of colour, researchers argue, can have important implications for our emotional and psychological states (Babin et al., 2003). Studies postulate that certain colours are correlated with specific moods and can resultantly determine psycho-emotional states. Accordingly, they can be used as a curative intervention in overcoming certain undesirable emotional or psychological states (Day \& Rich, 2009). "Colour psychology" thus counsels exposure to colours as beneficial for given ailments (Birren, 2006). In the context of art production and art education, this relationship (between mental state and colours) is explored in a more reflective and metacognitive fashion, foregrounding the interrelations between an artist's mental state and the kinds of colours they use to depict the same as well as the impact these colours have on the art viewer. For example, in situations where the artist is experiencing a bad mood or undergoing life problems/pressure, he or she may select colours which reflect these psycho-emotional states; they transpose their internal experiences into external compositions, using colour as an emotional signifier. For the art viewer, this impression evoked by the artist is transmitted by a similar putative correlation between colours and psycho-cognitive effects. For art students, colour psychology has related but distinct implications, for it factors into the formative training (Matherm, 2014).

\section{Methodology}

This paper uses mixed-methodology, combining psychology, anthropology, sociology, biographical criticism, and art criticism, using a qualitative framework to transpose insights from clinical therapeutic settings (colour psychology) to art production contexts. Particular emphases are placed on metacognitive processes and their relation to psycho-social interpretations of colour: as manifests in art producers and is experienced by art viewers. This paper uses case study example art works to demonstrate the way particular biographical details may be tracked against colour profiles (in art works) which evoke defined emotional states. The intention behind this methodological approach is demonstrate tangible interlinks between psycho-emotional states and the use of colour in artistic output. By making these interconnections apparent, this study seeks further to illuminate the cognitive mechanics of how colours come to be imbued with meaning by artists, and how these meanings are further decoded by spectators of arts. By shining light on this interactive process (between art producer, art product, and art viewer), this paper intends to elucidate metacognitive processes at work; these, in turn, may be useful reflexive tools for arts practitioners amateurs, professionals, and students. To reiterate, the research problem concerns how artists use colour to deal with emotions, to process complex mind states, and how this process can de dissected, examined, understood, and thus used as a metacognitive tool. 


\section{Efficacy of Art Therapy and Colour Psychology}

Concerning the psychological perspective, colour psychology comprises a sub-section of "Art Therapy", a general term which encapsulates a constellation of associated arts approaches to therapeutic ends. Concerning empirics: "Surprisingly, little theoretical or empirical work has been conducted to date on colour's influence on psychological functioning, and the work that has been done has been driven mostly by practical concerns, not scientific rigour" (Samina et al., 2005). Further, debate around the effects of colour on mood, how mood might conversely inform colour, are hotly contested; the subject is controversial, especially insomuch as it evokes discourses surrounding alternative medicine as "nonscientific" (Maier et al., 2007). The counterargument holds that art therapy's increasing popularity and prevalence are "qualitative" (and principally anecdotal) as opposed to "quantitative" proofs (Rubin, 1999). Nonetheless, certain (limited) empirical studies indicate that art therapy "might have a beneficial effect on reducing fatigue, tiredness, and psychological and spiritual distress, and in promoting coping" (Currow et al., 2015). Of course, the relatively limited quantitative support for art therapy is potentially due to the eclecticism of arts approaches, making it difficult to submit rigorous analytical frameworks on heterogenous practices, in any coherent manner. Arts therapies are varied as the arts they deploy (Michaels et al., 2015).

\section{Colour and Art Psychology for Practitioners and Students of Art}

From a sociological and anthropological view, colour's emotive power, mental health implications, and potential for shaping mind mood, is well established. Colour has both intuitive and symbolic-representational significance. Colours which evoke a positive feeling in the artist can conjure a positive mood; or the converse approach may be used to depict negative moods. Arguably, the artist summons this mood, and the spectator infers it, because of a common register (cultural or possibly inbuilt and by cognitive predisposition) in decoding emotional associations of colour. Hence, in the West at least, red often is associated with anger and passion; blue with melancholy; black with despair and death; white with purity; and so on. The "importance we attach to our perception of light and colour and its emotional effects upon us is not only celebrated by artists, poets and architects", it has long been seen clinically to "infleunce mood" (Best, 2017). For arts practioners, colour is used to "explore visual perception and to represent or evoke emotions. The psychological effects of colour, hue, saturation, and brightness" are understood to evoke particular "psychological responses" in the artists and the viewer (Schewe et al., 2011). These responses command proximal consistency across arts producers/spectators, albeit with margins for individual interpretations of these general emotional impressions. This is why the spectator, even if they have no direct knowledge of the artist, their mental state or intentions, can nonetheless experience similar emotions (in 
viewing the work) to those the artist felt (in producing it). Hence it is useful to make a distinction: between the effect of colour psychology on the artist (producing the work); and the effect of the work on the viewer. For the artist, who is experiencing "negative" psychological and emotional states, the effects of colour psychology could be used in a remedial sense. For instance, as Kaimal notes, "Anything that engages your creative mind the ability to make connections between unrelated things and imagine new ways to communicate-is good for you", and engages the brain to summon "information to make predictions about we might do and more importantly what we need to do next to survive and thrive" (Gharib, 2020). The engagement with colour can be a means to confront, navigate and process emotional states for the artist, helping them overcome bad moods or negative minds states conscious and unconscious. Specifically, this entails the artist selecting colours which are reflective (for them) of the problems they are facing at that time, whether they are able to precisely define these problems or not. Indeed, the "art-making process can be a powerful catalyst for the expression of unconscious material", and colour has an important role here: as a form of (psychological) "transference" for the art practitioner, allowing the art object to "embody" the emotions which the artist is dealing with (Rifkind et al., 2013).

For students, an awareness of colour psychology could be a vital asset in how they approach the art process, in that it can help them in understanding their own cognitive processes. A degree of metacognition in this respect might invest the arts student with an ability to leverage certain "negative" moods into positive creative acts (Gharib, 2020). This would involve active management of thoughtprocesses: where students take command of their own psycho-emotional impulses and direct them in positive ways. Further, a sensibility for colour psychology would logically enhance the student's ability to consciously craft the emotional register they seek. Following this logic, there is a clear continuity and interactivity between the art practitioner/teacher and the art student. Both are dealing with emotional phenomena in a highly reflexive manner. Thus it is the duty of the teacher/practitioner to impart to the student the metacognitive capabilities of self-analysis in colour psychology. In this manner, the student will not be overwhelmed or inhibited by poor mood or mind state; on the contrary, they will transmute this raw emotional matter into productive creative outcomes.

\section{Case Studies of Colour in Master Works}

Regarding art criticism and biographical criticism, we can examine how colour psychology in art processes helps artists "translate [emotions] into meaning", thereby to "connect to emotions", making active associations "between art process and cognitions" (Gharib, 2020). We can consider this in relation to examples from well-known artists: 1) Piet Mondrian; 2) Wassilly Kandinsky; 3) Edvard Munch; 4) Pablo Picasso.

Mondrian's Place de la Concorde was started in Paris but completed New York. In America, Mondrian added bolder colours, "new coloured lines" and 
"unbounded colour planes", signifying the artist's sense of promise and "optimism" in American art scene (see Figure 1) (Pitts-Rembert, 2018). By contrast, Modnrian's earlier works, completed in Europe, arguably evoke a sense of emotional suppression or limitation; the sense of being bounded (see Figure 1).

For Kandinsky, in Blue Mountain, "colour and line correspond directly to emotion", summoning a profound sense of "hope" embedded in this "apocalyptic" image. The artist himself notes that the two focal points are the "tangled lines" and the "moulded summit of the blue mountain", (see Figure 2) which are

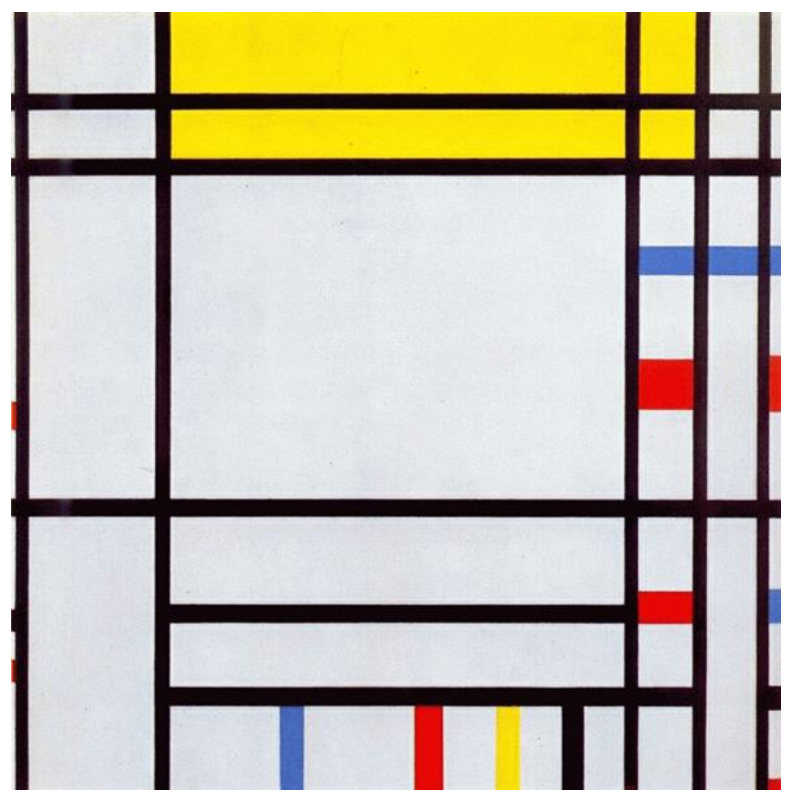

Figure 1. Piet Mondrian, Place de la Concorde (1938-1943).

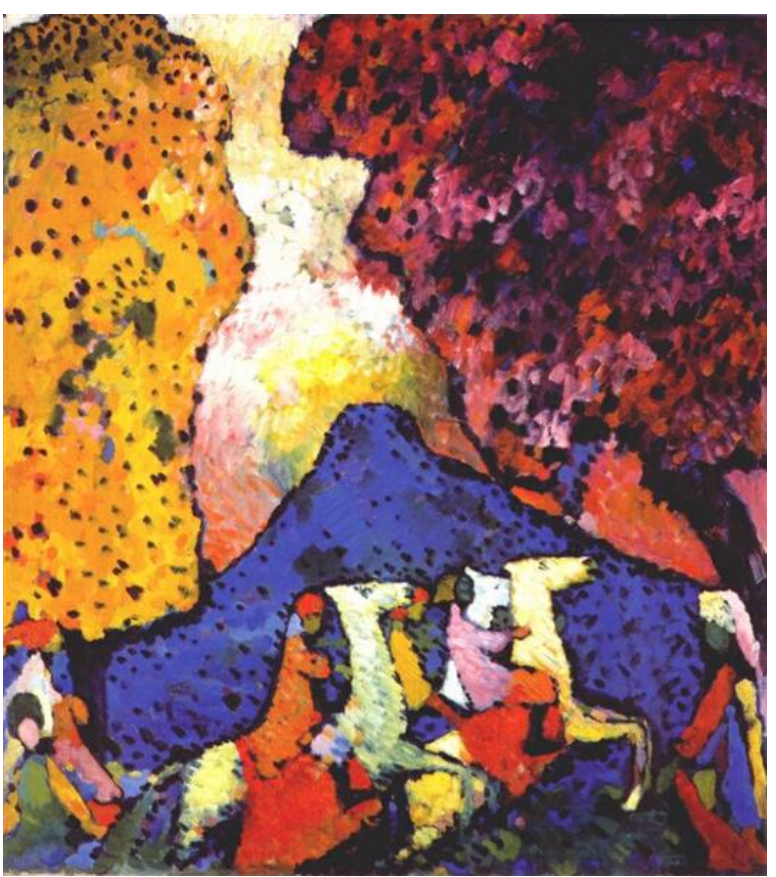

Figure 2. Wassilly Kandinsky, Blue Mountain (1908). 
separated by black lines; and that the "yellow is cold. This bright-fresh-cold to the sharp agitated (War) is the principal contrast of the picture" (Nici, 2015). The hope embedded in the image arguably reflects the artist's own positive sense of the future of art, in which a bold new aesthetics was inchoate. Munch's The Scream, with its harsh russet tones, strikes more of an aggressive and tormented tenor. While no definitive analysis of the work has been established (it evokes much debate as to its meaning) one can provisionally extract some sense of Scream's provenance in the artist's biography (see Figure 3). Munch, as scholars note, was "not happy", and famously stated that "disease and insanity were black angels on guard at my cradle"; he was further tormented by "alcoholism" and "agoraphobia" besides other "internal devils" (Butler, 1994). On this analysis, one could certainly read in the bold reds of the sky (see Figure 3 ) and the contorted icy blue mien of the screamer an evocation of internal torment, only amplified by the indifference of the dark blue-black passers-by. Picasso's The Old Guitarist contrasts starkly in mood with Mondrian's optimistic colour profile (see Figure 4), deriving from the artist's so-called "Blue Period". At this time, Picasso was living in poverty, as well as feeling depression over the recent suicide of a friend, with his works reflecting this state of mind. He created "icy blue paintings, revealing sadness and suffering in his characters, as in The Old Guitarist" (Glubok, 1994). Here, Picasso arguable embodies his sadness and grief (in transference) by embodying them in the painting. Thus the "icy" blues and sombre tone might be viewed as a form of expiation of the form his grief was taking; again, seeing art production and colour enact a remedial or curative effect.

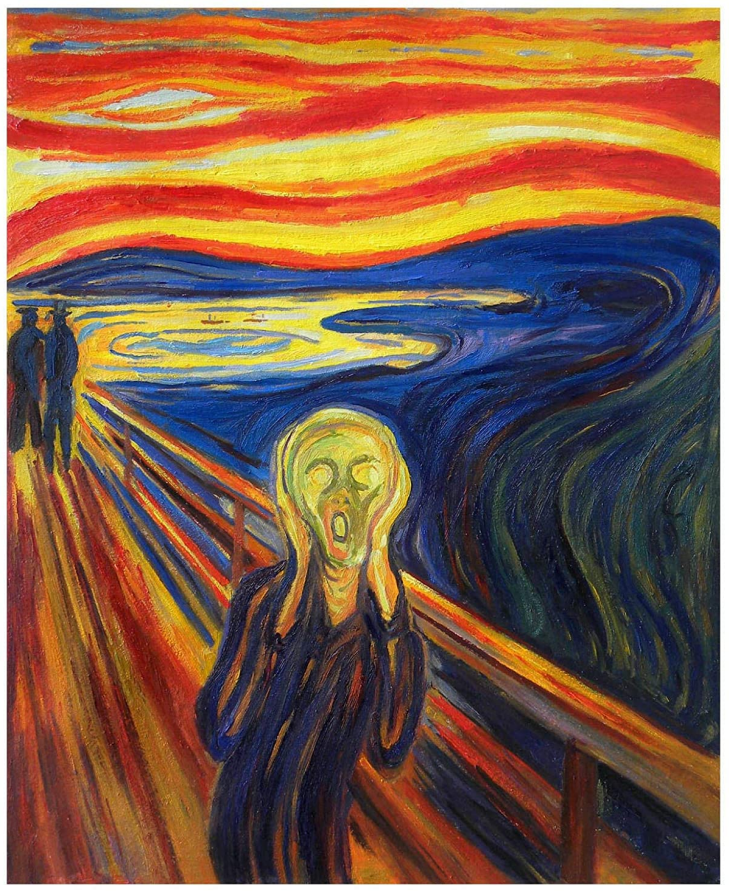

Figure 3. Edvard Munch, The Scream (1893). 


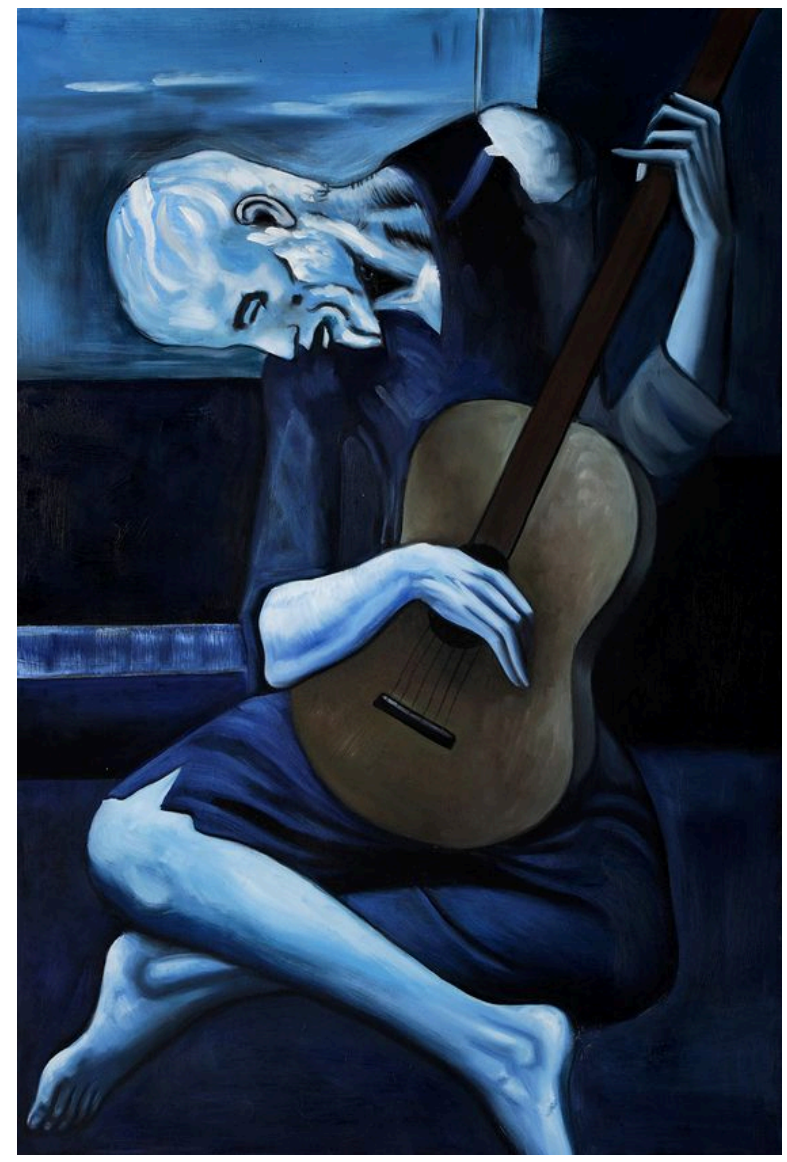

Figure 4. Pablo Picasso, The Old Guitarist (1903-1904).

\section{Conclusion}

Colour psychology and art therapy are important components in the creative and productive process because they evidently frame (physically and psycho-emotionally) human experience in profound ways. As this paper has sought to demonstrate, there is much in common with therapeutic approaches and artistic creations: seeing as both pertain to reflexive and analytical engagements with deep and often troubling emotions. In many instances, colour choices are a way to confront and process troubling emotions, by projecting them onto the canvas, embodying them in material form. Such creative use of colour can render tangible obscure and abstract emotions, which in turn facilitates the subject in navigating these mind states and moods. From the scholarly literature, as well as the case study examples, a strong case can be made the colour psychology is a potent element of art production, and often correlates directly with the artist's emotional state. Metacognitive awareness of these psycho-emotional dynamics is beneficial for both arts practitioners and art students because it potentially allows for greater control over the frequently obscure and mysterious artistic process.

\section{Conflicts of Interest}

The author declares no conflicts of interest regarding the publication of this paper. 


\section{References}

Babin, B. J., Hardesty, D. M., \& Suter, T. A. (2003). Colour and Shopping Intentions: The Intervening Effect of Price Fairness and Perceived Affect. Journal of Business Research, 56, 541-551. https://doi.org/10.1016/S0148-2963(01)00246-6

Best, J. (2017). Colour Design: Theories and Applications. Elsevier Science.

Birren, F. (2006). Colour Psychology and Color Therapy: A Factual Study of the Influence of Color on Human Life. Kessinger.

Butler, C. (1994). Early Modernism: Literature Music and Painting in Europe, 1900-1916. Clarendon Press.

Currow, D. C., Fallon, M., Cherny, N., Portenoy, R. K., \& Kaasa, S. (2015). Oxford Textbook of Palliative Medicine. OUP.

Day, T. D., \& Rich, C. (2009). A Theoretical Model for Transforming the Design of Healing Spas: Color and Platonic Solids. Health Environments Research \& Design Journal, 2, 84-107. https://doi.org/10.1177/193758670900200307

Gharib, M. (2020). Feeling Artsy? Here's How Making Art Helps Your Brain. National Public Radio.

https://www.npr.org/sections/health-shots/2020/01/11/795010044/feeling-artsy-hereshow-making-art-helps-your-brain

Glubok, S. (1994). Painting. Scribner's Press.

Elliot, A. J., Maier, M. A., Moller, A. C., Friedman, R., \& Meinhardt, J. (2007). Colour and Psychological Functioning: The Effect of Red on Performance Attainment. Journal of Experimental Psychology: General, 136, 154-168. https://doi.org/10.1037/0096-3445.136.1.154

Matherm, G. (2014). The Psychology of Visual Art: Eye, Brain and Art (p. 31). Cambridge University Press. https://doi.org/10.1017/CBO9781139030410

Michaels, D., Ashley, J., Hyde, I. V. S., \& Bell, S. (2015). Art Therapy with Neurological Conditions. Jessica Kingsley Publishers.

Nici, J. (2015). Famous Works of Art-And How They Got That Way. Rowman \& Littlefield Publishers.

Pitts-Rembert, V. (2018). Piet Mondrian. Baseline Ltd.

Rifkind, G., Terry, K., \& Dalley, T. (2013). Three Voices of Art Therapy (Psychology Revivals): Image, Client, Therapist. Taylor \& Francis.

Rubin, J. A. (1999). Art Therapy: An Introduction. Brunner/Mazel.

Samina, T., Azeemi, Y., \& Raza, S. M. (2005). A Critical Analysis of Chromo Therapy and Its Scientific Evolution. Evidence-Based Complementary and Alternative Medicine, 2, 481-488. https://doi.org/10.1093/ecam/neh137

Schewe, K., Liddle, S. W., \& Zhou, X. (2011). Database and Expert Systems Applications: 22nd International Conference, DEXA 2011, Bilbao, Spain, August 29-September 2, 2011, Proceedings, Part II. Springer.

Tilley, R. J. D. (2010). Colour and the Optical Properties of Materials: An Exploration of the Relationship between Light, the Optical Properties of Materials and Colour. Wiley. https://doi.org/10.1002/9780470974773 